\title{
Improvement of cisplatin-related renal dysfunction by synthetic ghrelin: a prospective randomised phase II trial
}

Yoshitomo Yanagimoto ${ }^{1}$, Shuji Takiguchi ${ }^{\star}, 1$, Yasuhiro Miyazaki ${ }^{1}$, Tomoki Makino ${ }^{1}$, Tsuyoshi Takahashi ${ }^{1}$, Yukinori Kurokawa ${ }^{1}$, Makoto Yamasaki ${ }^{1}$, Hiroshi Miyata ${ }^{1}$, Kiyokazu Nakajima ${ }^{1}$, Hiroshi Hosoda ${ }^{2}$, Kenji Kangawa ${ }^{2}$, Masaki Mori ${ }^{1}$ and Yuichiro Doki ${ }^{1}$

${ }^{1}$ Department of Gastroenterological Surgery, Osaka University Graduate School of Medicine, 2-2, E-2, Yamadaoka, Suita 565-0871, Japan and 'Department of Biochemistry, National Cardiovascular Center Research Institute, 5-7-1, Fujishirodai, Suita 565-8565, Japan

Background: Ghrelin, a 28-amino acid peptide predominantly produced by the stomach, exerts powerful renal protective effects by increasing levels of insulin-like growth factor-1 (IGF-1). The aim of this study was to evaluate the effects of ghrelin on the incidence of renal dysfunction in patients receiving cisplatin-based chemotherapy.

Methods: Forty patients with oesophageal cancer receiving cisplatin-based chemotherapy were assigned to either the ghrelin group $(n=20)$, which received ghrelin $\left(0.5 \mu \mathrm{g} \mathrm{kg}^{-1} \mathrm{~h}^{-1}\right)$ for 5 days, or a placebo group $(n=20)$. The primary endpoint was serum creatinine. Secondary endpoints were serum cystatin $\mathrm{C}$, chemotherapy-related adverse events, changes in serum ghrelin-related hormone levels, correlation between markers of renal injury and hormone concentrations, and effects on the second cycle of chemotherapy.

Results: Blood acyl ghrelin, total ghrelin, and IGF-1 concentrations on day 4 were significantly higher in the ghrelin group. The renal dysfunction, serum creatinine and cystatin $C$ levels, dose reduction, and delay in the initiation of the second cycle of chemotherapy were lower in the ghrelin group than in the control group. Serum creatinine levels were significantly correlated with serum IGF-1 levels.

Conclusion: Continuous synthetic ghrelin administration during cisplatin-based chemotherapy attenuated renal dysfunction and harmful effects on subsequent chemotherapy, possibly by increasing IGF-1 levels.

Cisplatin is a major antineoplastic drug used for various solid tumours, including oesophageal cancer (Engstrom et al, 1983). Cisplatin is generally used in combination with other anticancer agents (Iizuka et al, 1992; Ilson et al, 1999; Hara et al, 2013). Cisplatin-based combination chemotherapy has high response rates in the adjuvant setting and with chemoradiation therapy, which has improved long-term outcomes in patients with oesophageal cancer (Minsky et al, 2002; Ando et al, 2012). However, cisplatin is primarily excreted by the kidneys and it has been associated with an increased risk of nephrotoxicity.
Cisplatin-associated nephrotoxicity often leads to dose reduction or discontinuation of chemotherapy. Both outcomes can affect not only patient quality of life (QOL) but also prognosis. To prevent cisplatin-associated nephrotoxicity, patients receive hydration and a diuretic such as mannitol and furosemide (Hayes et al, 1977; Ostrow et al, 1981). However, not all cases of nephrotoxicity have been prevented. (Hara et al, 2013). A novel method to prevent cisplatin-associated nephrotoxicity is expected to be developed.

Discovered in 1999, ghrelin is a peptide hormone that is an endogenous ligand for the growth hormone $(\mathrm{GH})$ secretagogue

*Correspondence: Dr S Takiguchi; E-mail: stakiguchi@gesurg.med.osaka-u.ac.jp

Received 4 February 2016; revised 12 April 2016; accepted 6 May 2016; published online 2 June 2016

(c) 2016 Cancer Research UK. All rights reserved 0007 - 0920/16 
receptor (Kojima et al, 1999). Ghrelin has several physiological functions, including secretion of GH (Kojima et al, 1999; Nagaya et al, 2001) and insulin-like growth factor-1 (IGF-1; Akamizu and Kangawa, 2006; Veldhuis et al, 2008), promotion of the appetite signal, and stimulation of gastrointestinal activity in humans (Takata et al, 2015a). In addition, both in vivo and in vitro studies have shown that ghrelin, via promoting IGF-1 release, exerts a powerful protective effect against damage of the heart, gastrointestinal tract, liver, nervous system, and kidney (Gobe et al, 1999; Takeda et al, 2006; Vasileiou et al, 2013).

Our previous study showed that serum ghrelin concentrations decrease to $\sim 60 \%$ during cisplatin-based chemotherapy as compared with pre-chemotherapy levels (Yamamoto et al, 2013; Yanagimoto et al, 2016). In addition, plasma acyl ghrelin is a predictor of renal dysfunction associated with cisplatin-based chemotherapy, and decreased levels of plasma ghrelin are correlated with renal dysfunction during chemotherapy (Yanagimoto et al, 2016). These results suggest that ghrelin may act as a protective factor for the kidney via promoting the release of IGF-1 during cisplatin-based chemotherapy. In this study, we conducted a clinical randomised trial to evaluate the effectiveness of ghrelin administration for reducing nephrotoxicity in patients receiving cisplatin-based chemotherapy.

\section{MATERIALS AND METHODS}

Study patients. This prospective, randomised, placebo-controlled phase II study enrolled 40 patients with squamous oesophageal cancer receiving a combination of docetaxel, cisplatin, and 5 -fluorouracil chemotherapy (DCF). The Human Ethics Review Committee of Osaka University School of Medicine approved the study protocol, and written informed consent was obtained from each patient before study entry in accordance with the Declaration of Helsinki Principles. This study was registered on the University Hospital Medical Information Network (UMIN 000018162). Patient enrolment began in June 2014 and ended in June 2015.

The eligibility criteria for the study were as follows: (1) primary squamous oesophageal cancer with planned DCF chemotherapy; (2) creatinine clearance $>60 \mathrm{ml} \mathrm{min}^{-1}$; (3) no renal disease; (4) no previous treatment; (5) age between 20 and 80 years; (6) adequate function of major organs; (7) Eastern Cooperative Oncology Group performance status score of 0 or 1 ; and (8) provision of written informed consent. The exclusion criteria were as follows: (1) severe comorbid conditions; (2) another active malignancy; (3) study participation judged as inappropriate by the physician in charge; (4) combination radiation therapy; and (5) lactation or pregnancy.

A section of the Department of Gastroenterological Surgery, Osaka University Medical School, served as the coordinating centre and was responsible for creating the treatment allocation code using a computer-generated randomisation table. Patients were randomised to receive intravenous infusion of either synthetic human ghrelin or placebo in a $1: 1$ ratio. Treatment allocation was arranged before the start of chemotherapy. The study was performed in a double-blind manner. Patients and the primary treating physician were blinded and an independent researcher assessed outcomes.

Synthetic human ghrelin and placebo control. Synthetic human ghrelin (active form) was obtained from the Peptide Institute (Osaka, Japan). Ghrelin was dissolved in distilled water with $3.75 \%$ D-mannitol and sterilised by passage through a $0.22 \mu \mathrm{m}$ filter. Ghrelin was stored as a $2 \mathrm{ml}$ preparation (each containing $210 \mu \mathrm{g}$ active ghrelin and $75 \mathrm{mg} \mathrm{D}$-mannitol) in sterile vials at $-80^{\circ} \mathrm{C}$ until administration. The Laboratory for Clinical Investigation, Osaka University Hospital, confirmed that there were no traces of endotoxin or pyrogens in the ghrelin solution. Placebo control included the same dose of D-mannitol as the prepared ghrelin solution in order to equalise dose of D-mannitol between the groups.

Chemotherapy regimen. The DCF regimen was comprised of docetaxel $\left(70 \mathrm{mg} \mathrm{m}^{-2}\right)$ and cisplatin $\left(70 \mathrm{mg} \mathrm{m}^{-2}\right)$ on day 1 and continuous infusion of 5-fluorouracil $\left(700 \mathrm{mg} \mathrm{m}^{-2}\right)$ for 5 days in a 21-day cycle (Yamasaki et al, 2011). All patients were premedicated intravenously with the neurokinin-1 receptor-selective antagonist fosaprepitant meglumine $(150 \mathrm{mg})$, the serotonin (5-hydroxytryptamine) receptor antagonist palonosetron hydrochloride $(0.75 \mathrm{mg})$, and dexamethasone sodium phosphate $(6.6 \mathrm{mg})$, all infused $1 \mathrm{~h}$ prior to the administration of docetaxel on day 1 . On the mornings of days 2 and 3, patients received intravenous dexamethasone sodium phosphate $(6.6 \mathrm{mg})$. Patients were hydrated with the following volumes of solution: $1000 \mathrm{ml}$ on day $0,3500 \mathrm{ml}$ on day 1 , $3000 \mathrm{ml}$ on days 2 and 3, $2000 \mathrm{ml}$ on days 4 and 5, and $1000 \mathrm{ml}$ on day 6.

Adverse events and criteria for the second cycle of chemotherapy. Adverse events were graded based on the most severe toxicity during the first cycle (days 1-21) according to the Common Terminology Criteria for Adverse Events (CTCAE) version 4.0 (Health and Services, 2009). When Grade 1 or higher creatinine increase occurred or was expected to occur, patients received hydration with or without a diuretic.

The second cycle of chemotherapy was initiated after adverse events from the first cycle were resolved. Dose modifications in the second cycle were based on treatment-related adverse events observed during the first cycle. In the second cycle of chemotherapy, the dose of docetaxel, cisplatin, and 5-fluorouracil were reduced by $20 \%$ for a Grade 4 haematologic adverse event lasting $>5$ days, Grade 3 febrile neutropenia lasting $>5$ days, or a Grade 3 nonhematologic adverse event. The dose of cisplatin was reduced by $20 \%$ for Grade 2 creatinine increase.

Clinical response to the first cycle of chemotherapy was assessed with the Response Evaluation Criteria in Solid Tumors (RECIST; Therasse et al, 2000) between 2 and 3 weeks after the initiation of chemotherapy using computed tomography (CT) and endoscopy. When a tumour was responsive to chemotherapy, that is, stable disease (SD), partial response (PR), or complete response according to RECIST, DCF was continued during the second cycle. Conversely, if there was progressive disease (PD), development of a serious adverse event, or based on the judgment of the attending physicians, patients received another chemotherapy regimen that did not include DCF in the second cycle of chemotherapy, surgical treatment, or best supportive care. In addition, when patients with clinical T4 stage disease did not demonstrate a good response to the first cycle of DCF (residual T4 disease is still expected after additional DCF), patients received a combination of chemotherapy and radiation in the second cycle.

Study protocol and endpoints. The study protocol is summarised in Supplementary Figure 1. Patients who were assigned to the ghrelin group received continuous ghrelin administration $\left(0.5 \mu \mathrm{g} \mathrm{kg}^{-1} \mathrm{~h}^{-1}\right)$ between day 0 and day 4 of chemotherapy, which was started concurrently with pre-chemotherapy hydration. Ghrelin was diluted to a final volume of $48 \mathrm{ml}$ with saline, and the solution was administered at a rate of $2 \mathrm{ml} \mathrm{h}^{-1}$ using an infusion pump through a central venous catheter inserted into the right subclavian vein. Patients in the placebo group received continuous $\mathrm{D}$-mannitol infusion $\left(178.5 \mu \mathrm{g} \mathrm{kg}^{-1} \mathrm{~h}^{-1}\right)$, which was diluted to a final volume of $48 \mathrm{ml}$ with saline and administered using the same procedure as in the ghrelin group.

The primary endpoint of this study was change in serum creatinine during the first cycle of chemotherapy. The secondary endpoints were serum cystatin $\mathrm{C}$, a promising new marker of renal failure independent of muscle mass, age, or sex (Pucci et al, 2007; 
Tanaka et al, 2007); chemotherapy-related adverse events; changes in ghrelin-related hormone levels; correlation between serum creatinine, cystatin $\mathrm{C}, \mathrm{GH}$, and IGF-1 concentrations; ratio of the DCF dose during the second cycle to the dose in the first cycle; and delay in the initiation of the second cycle of DCF chemotherapy. Blood samples were collected before breakfast after an overnight fast before chemotherapy and on days 2, 4, 8, 11, and 15 of the first cycle of chemotherapy.

Analysis of plasma ghrelin and serum cystatin C, GH, and IGF-1 levels. Blood samples were transferred immediately into chilled tubes containing disodium ethylene diamine tetra-acetic acid and aprotinin, centrifuged at $4{ }^{\circ} \mathrm{C}$, separated for serum sampling, and stored at $-80^{\circ} \mathrm{C}$. Plasma samples were mixed with a $10 \%$ volume of $1 \mathrm{M}$ hydrochloric acid before storage at $-80^{\circ} \mathrm{C}$. Plasma acyl ghrelin and desacyl ghrelin concentrations were measured with a sandwich-type enzyme immunoassay kit (Mitsubishi Kagaku Iatron, Inc., Tokyo, Japan). Total plasma ghrelin concentration was calculated as acyl ghrelin plus desacyl ghrelin concentration. Serum GH, IGF-1, and cystatin C were measured with electrochemiluminescence immunoassays using the Elecsys human GH kit (Roche Diagnostics, Basel, Switzerland), an immunoradiometric assay (FUJIREBIO, Inc., Tokyo, Japan), and latex agglutination turbidimetry (LSI Medience Corporation, Tokyo, Japan), respectively.

Sample size and statistical analysis. On the basis of our previous study, we estimated that the mean serum creatinine in the placebo group would be $1.1 \pm 0.3 \mathrm{mg} \mathrm{dl}^{-1}$ (Yanagimoto et al, 2016). The sample size calculation was based on a $20 \%$ improvement by ghrelin administration, power of $80 \%$ and alpha of $10 \%$. At least 18 patients were required per study group. Assuming that $\sim 10 \%$ of the patients in each group would not complete the study, the initial proposal aimed to recruit 20 patients to each group.

Continuous variables are expressed as means \pm s.d. unless otherwise stated. Statistical differences between groups were calculated using Student's $t$-test, Mann-Whitney $U$-test, and $\chi^{2}$ test as appropriate. The relationship between parameters was investigated using Pearson's correlation analysis. Statistical significance was set at $P<0.05$. JMP (version 10.0) software (SAS Institute, Cary, NC, USA) was used to perform all analyses.

\section{RESULTS}

Patient characteristics. In total, 40 enrolled patients were randomised into the ghrelin group $(n=20)$ or the placebo group $(n=20)$. All patients received full-dose DCF chemotherapy and the planned dose of ghrelin or placebo during the first cycle. No adverse events associated with ghrelin administration were observed during the study period, and all patients were able to undergo evaluation. There were no significant differences in background characteristics, including age, gender, body mass index, tumour location, and clinical cancer stage (Table 1).

Changes in hormone status. Table 2 shows the effects of ghrelin administration on plasma ghrelin, serum GH, and serum IGF-1 levels, which were measured before chemotherapy and on day 4 . There were no significant differences in pre-chemotherapy levels of hormones between the ghrelin and control groups. Day 4 plasma acyl ghrelin levels were significantly higher in the ghrelin group compared with the placebo group $(348.9 \pm 136.3 v \mathrm{~s}$ $\left.13.8 \pm 12.6 \mathrm{fmol} \mathrm{ml}^{-1} ; P<0.001\right)$. On day 4 , the ghrelin group had higher levels of total ghrelin, serum GH, and serum IGF-1 than the placebo group (total ghrelin, $1046.4 \pm 180.3 v s 108.0 \pm 85.7 \mathrm{fmol} \mathrm{ml}^{-1}$; $P<0.001 ; \mathrm{GH}, 4.1 \pm 3.1$ vs $1.5 \pm 1.3 \mathrm{ng} \mathrm{ml}^{-1} ; P<0.001 ; \mathrm{IGF}-1$, $183.0 \pm 58.2$ vs $\left.112.8 \pm 37.1 \mathrm{ng} \mathrm{ml}^{-1} ; P<0.001\right)$.
Table 1. Characteristics of the study patients

\begin{tabular}{|c|c|c|c|}
\hline & $\begin{array}{l}\text { Ghrelin group } \\
\quad(n=20)\end{array}$ & $\begin{array}{c}\text { Placebo } \\
\text { group }(n=20)\end{array}$ & $P$-value \\
\hline Age, years & $67.5 \pm 6.2$ & $66.6 \pm 7.4$ & 0.828 \\
\hline $\begin{array}{l}\text { Gender, } n \\
\text { Male } \\
\text { Female }\end{array}$ & $\begin{array}{r}18 \\
2\end{array}$ & $\begin{array}{r}19 \\
1\end{array}$ & 0.548 \\
\hline BMI, $\mathrm{kgm}^{-2}$ & $20.2 \pm 2.5$ & $21.7 \pm 3.6$ & 0.204 \\
\hline $\begin{array}{l}\text { Tumour location, } n \\
\text { Cervical } \\
\text { Upper thoracic } \\
\text { Middle thoracic } \\
\text { Lower thoracic } \\
\text { Abdominal }\end{array}$ & $\begin{array}{l}2 \\
7 \\
7 \\
4 \\
0\end{array}$ & $\begin{array}{r}2 \\
3 \\
11 \\
4 \\
0\end{array}$ & 0.468 \\
\hline $\begin{array}{l}\text { Clinical UICC stage, } n \\
\text { I } \\
\text { II } \\
\text { III } \\
\text { IV }\end{array}$ & $\begin{array}{r}3 \\
3 \\
11 \\
3\end{array}$ & $\begin{array}{l}4 \\
5 \\
8 \\
3\end{array}$ & 0.773 \\
\hline $\begin{array}{l}\text { Abbreviations: } \mathrm{BMI}=\text { body } \\
\text { are expressed as means } \pm\end{array}$ & index; UICC $=$ Inte & ational Union Aga & Cancer. Data \\
\hline
\end{tabular}

Table 2. Results of ghrelin-related hormone levels before ghrelin administration and on day 4 of chemotherapy

\begin{tabular}{|c|c|c|c|}
\hline & $\begin{array}{l}\text { Ghrelin group } \\
\quad(n=20)\end{array}$ & $\begin{array}{c}\text { Placebo } \\
\text { group }(n=20)\end{array}$ & $P$-value \\
\hline \multicolumn{4}{|c|}{ Acyl ghrelin, fmol ml $\mathrm{ml}^{-1}$} \\
\hline Before chemotherapy & $28.8 \pm 31.2$ & $25.0 \pm 36.2$ & 0.491 \\
\hline Day 4 & $348.9 \pm 136.3$ & $13.8 \pm 12.6$ & $<0.001$ \\
\hline \multicolumn{4}{|c|}{ Total ghrelin, fmol ml $\mathrm{ml}^{-1}$} \\
\hline Before chemotherapy & $222.0 \pm 278.1$ & $161.0 \pm 140.7$ & 0.457 \\
\hline Day 4 & $1046.4 \pm 180.3$ & $108.0 \pm 85.7$ & $<0.001$ \\
\hline \multicolumn{4}{|c|}{ Growth hormone, $\mathrm{ng} \mathrm{ml}^{-1}$} \\
\hline Before chemotherapy & $1.3 \pm 0.8$ & $1.1 \pm 1.1$ & 0.168 \\
\hline Day 4 & $4.1 \pm 3.1$ & $1.5 \pm 1.3$ & $<0.001$ \\
\hline \multicolumn{4}{|c|}{ Insulin-like growth factor-1, $\mathrm{ng} \mathrm{ml}^{-1}$} \\
\hline Before chemotherapy & $119.1 \pm 39.5$ & $105.2 \pm 41.0$ & 0.323 \\
\hline Day 4 & $183.0 \pm 58.2$ & $112.8 \pm 37.1$ & $<0.001$ \\
\hline
\end{tabular}

Adverse events. Table 3 demonstrates the haematological and nonhematological adverse events associated with chemotherapy. In the ghrelin and placebo groups, there were 18 and 9 participants with Grade 0 renal dysfunction, 2 and 9 with Grade 1, and 0 and 2 with Grade 2, respectively. Renal dysfunction was more common in the control group than in the ghrelin group $(P=0.002)$. Other adverse events, which included myelosuppression, nausea, mucosal damage, electrolyte abnormalities, and fatigue, occurred in similar proportions in the two groups.

Effect on renal function. To assess the effect of ghrelin administration on renal function, serum creatinine and cystatin $\mathrm{C}$ levels were compared between the two groups. Serum creatinine levels on days 8 , 11 , and 15 were significantly lower in the ghrelin group than in the placebo group (day 8, $0.83 \pm 0.17$ vs $1.04 \pm 0.24 \mathrm{mg} \mathrm{dl}^{-1} ; P=0.004$; day $11,0.88 \pm 0.19$ vs $1.22 \pm 0.40 \mathrm{mg} \mathrm{dl}^{-1} ; P<0.001$; day 15 , $0.84 \pm 0.13$ vs $\left.1.12 \pm 0.38 \mathrm{mg} \mathrm{dl}^{-1}, P=0.005\right)$. Serum cystatin $C$ levels on day 15 were also significantly lower in the ghrelin group than in the placebo group $\left(1.01 \pm 0.22\right.$ vs $0.82 \pm 0.12 \mathrm{mgl}^{-1}$, $P=0.005$; Figure 1).

Correlation between renal function and blood hormone concentrations. Figure 2 shows the relationship between renal function (peak creatinine and cystatin $\mathrm{C}$ levels during chemotherapy) 
Table 3. Summary of adverse events ${ }^{a}$

\begin{tabular}{|c|c|c|c|}
\hline & $\begin{array}{l}\text { Ghrelin } \\
(n=20)\end{array}$ & $\begin{array}{l}\text { Placebo } \\
(n=20)\end{array}$ & $P$-value \\
\hline \multicolumn{4}{|c|}{ Haematologic } \\
\hline \multicolumn{4}{|c|}{ Neutropenia } \\
\hline Grade 0 & 0 & 0 & 0.311 \\
\hline Grade 1-2 & 1 & 0 & \\
\hline Grade 3-4 & 19 & 20 & \\
\hline \multicolumn{4}{|c|}{ Neutropenic fever } \\
\hline Grade 0 & 16 & 13 & 0.288 \\
\hline Grade 1-2 & 0 & 0 & \\
\hline Grade 3-4 & 4 & 7 & \\
\hline \multicolumn{4}{|c|}{ Lymphocytopenia } \\
\hline Grade 0 & 0 & 0 & 0.342 \\
\hline Grade 1-2 & 9 & 12 & \\
\hline Grade 3-4 & 11 & 8 & \\
\hline \multicolumn{4}{|l|}{ Anaemia } \\
\hline Grade 0 & 0 & 0 & 0.311 \\
\hline Grade 1-2 & 20 & 19 & \\
\hline Grade 3-4 & 0 & 1 & \\
\hline \multicolumn{4}{|c|}{ Thrombocytopenia } \\
\hline Grade 0 & 8 & 7 & 0.587 \\
\hline Grade 1-2 & 12 & 12 & \\
\hline Grade 3-4 & 0 & 1 & \\
\hline \multicolumn{4}{|c|}{ Non-haematologic } \\
\hline \multicolumn{4}{|c|}{ Anorexia } \\
\hline Grade 0 & 0 & 2 & 0.221 \\
\hline Grade 1-2 & 12 & 8 & \\
\hline Grade 3-4 & 8 & 10 & \\
\hline \multicolumn{4}{|l|}{ Nausea } \\
\hline Grade 0 & 1 & 3 & 0.313 \\
\hline Grade 1-2 & 9 & 5 & \\
\hline Grade 3-4 & 10 & 12 & \\
\hline \multicolumn{4}{|l|}{ Vomiting } \\
\hline Grade 0 & 18 & 15 & 0.212 \\
\hline Grade 1-2 & 2 & 5 & \\
\hline Grade 3-4 & 0 & 0 & \\
\hline \multicolumn{4}{|l|}{ Mucositis } \\
\hline Grade 0 & 6 & 11 & 0.264 \\
\hline Grade 1-2 & 13 & 8 & \\
\hline Grade 3-4 & 1 & 1 & \\
\hline \multicolumn{4}{|l|}{ Diarrhoea } \\
\hline Grade 0 & 0 & 3 & 0.184 \\
\hline Grade 1-2 & 13 & 10 & \\
\hline Grade 3-4 & 7 & 7 & \\
\hline \multicolumn{4}{|c|}{ Renal toxicity } \\
\hline Grade 0 & 18 & 9 & 0.002 \\
\hline Grade 1-2 & 2 & 11 & \\
\hline Grade 3-4 & 0 & 0 & \\
\hline \multicolumn{4}{|c|}{ Hyponatremia } \\
\hline Grade 0 & 4 & 4 & 1.000 \\
\hline Grade 1-2 & 10 & 10 & \\
\hline Grade 3-4 & 6 & 6 & \\
\hline \multicolumn{4}{|l|}{ Fatigue } \\
\hline Grade 0 & 1 & 2 & 0.413 \\
\hline Grade 1-2 & 15 & 11 & \\
\hline Grade 3-4 & 4 & 7 & \\
\hline
\end{tabular}

and blood hormone levels (serum GH and IGF-1 levels on day 4). Serum creatinine levels were significantly correlated with serum IGF-1 levels $(R=0.366, P=0.022)$. However, there was no statistically significant correlation observed between serum creatinine and serum GH levels $(R=0.161, P=0.321)$, serum cystatin $\mathrm{C}$ and serum $\mathrm{GH}$ levels $(R=0.179, P=0.724)$, and serum cystatin $\mathrm{C}$ and IGF-1 levels $(R=0.163, P=0.316)$.

Effect on the second cycle of chemotherapy. In the ghrelin group, the second cycle of treatment was changed to chemoradiation in two patients. Although patients had SD during the first cycle of chemotherapy, tumour invasion into neighbouring structures (clinical T4 disease) had not resolved. One patient with SD received best supportive care. DCF was switched to another regimen in one patient who had $\mathrm{PD}$. In the control group, curative surgery after the first cycle of chemotherapy was performed in four patients. Two of these patients had PD and the other two patients did not receive a second cycle of DCF due to chemotherapy-related adverse events, despite a PR. The remaining 16 patients in each group received a second cycle of DCF. To assess the effect of ghrelin administration on the second cycle of chemotherapy, the dose ratio and delay in the initiation of the second cycle of DCF of the two groups were compared (Supplementary Figure 2).

Patients in the ghrelin group received a significantly higher dose during the second cycle of DCF compared with the control group (docetaxel, $93.9 \pm 9.6$ vs $86.5 \pm 10.1 \%$; $P=0.016$; cisplatin, $92.7 \pm 10.1$ vs $83.0 \pm 13.6 \% ; P=0.012$; 5-fluorouracil, $93.9 \pm 9.6$ vs $85.5 \pm 9.3 \% ; P=0.022$ ). Initiation of the second cycle of DCF was delayed in one patient in the ghrelin group and six patients in the placebo group. One patient in the ghrelin group and five patients in the placebo group had prolonged renal dysfunction, and one patient in the placebo group had both prolonged renal dysfunction and a duodenal ulcer. Almost all adverse events other than renal dysfunction were resolved by the initiation of the second cycle of chemotherapy. The ghrelin group had a shorter delay in the initiation of the second cycle of DCF than the control group $(0.3 \pm 1.0$ vs $3.4 \pm 3.8$ days; $P=0.040$; Table 4$)$.

\section{DISCUSSION}

In this prospective randomised trial, we demonstrated that continuous synthetic ghrelin administration during cisplatin-based chemotherapy successfully attenuates renal dysfunction and harmful effects on the second cycle of chemotherapy. To the best of our knowledge, this is the first study to establish the renal protective effect of synthetic ghrelin administration in patients receiving cisplatin-based chemotherapy.

Cisplatin is a major antineoplastic drug used for the treatment of various solid tumours. It exerts its antineoplastic effect by cisplatin-DNA crosslinking (Yao et al, 2007). Approximately $28-6 \%$ of patients treated with more than $50 \mathrm{mg} \mathrm{m}^{-2}$ of cisplatin experience renal dysfunction and up to $20 \%$ may experience severe renal dysfunction (Gonzales-Vitale et al, 1977; Yao et al, 2007; Dahal et al, 2014). Cisplatin-associated renal dysfunction is usually transient and reversible; however, $\sim 40 \%$ of patients with renal dysfunction go on to develop irreversible renal failure despite adequate therapy (Kidera et al, 2014) and progressively increasing creatinine, leading to temporal dialysis (Gaspari et al, 2010; Kobayashi et al, 2014). Although this renal dysfunction may not be life threatening, it can limit the ability to deliver subsequent chemotherapy, which eventually compromises outcome (Jacobs et al, 1991).

Recently, the mechanism of cisplatin-induced nephrotoxicity has been clarified. Cisplatin is rapidly distributed into tissue at high concentrations. It is primarily excreted by the kidneys. Cisplatin is freely filtered by the glomerulus and taken up into renal tubular cells, mostly by a transport-mediated process. Cisplatin is at least partially metabolised into toxic species and has multiple intracellular effects, including direct cytotoxicity, stimulation of proinflammatory factors such as tumour necrosis factor- $\alpha$ (TNF- $\alpha)$, activation of mitogen-activated protein kinase, activation of the expression of vasoactive mediators, and production of reactive oxygen species (ROS). These mechanisms induce fibrosis around the tubules, DNA damage, mitochondrial dysfunction, tubular apoptosis, reduced renal perfusion, and decreased glomerular filtration rate. Consequently, renal dysfunction is due to tubular damage (Zwelling and Kohn, 1979; Huang et al, 2001; 

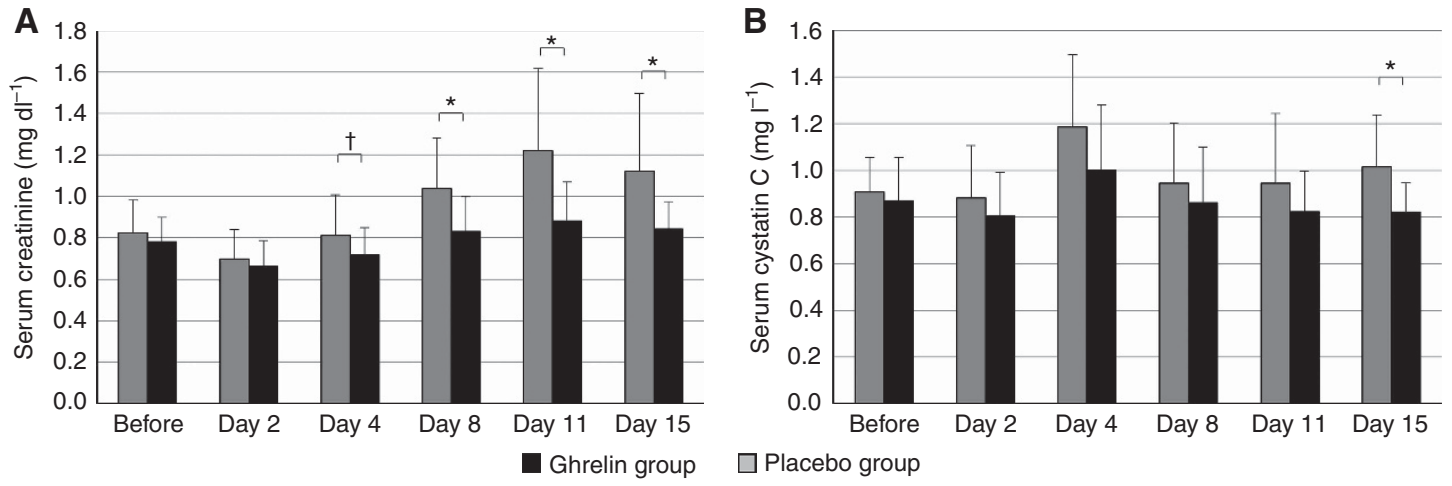

Figure 1. Change in (A) serum creatinine and (B) serum cystatin $C$ levels during docetaxel, cisplatin, and 5 -fluorouracil combination chemotherapy. Serum creatinine and cystatin $C$ were measured before chemotherapy and on days $2,4,8,11$, and 15 . Serum creatinine levels on days 8 , 11 , and 15 were significantly lower in the ghrelin group than in the placebo group. Serum cystatin $C$ levels on day 15 were also significantly lower in the ghrelin group than in the placebo group. ${ }^{\star} P<0.05$ between the ghrelin and placebo groups. ${ }^{\dagger} P<0.1$ between the ghrelin and placebo groups.
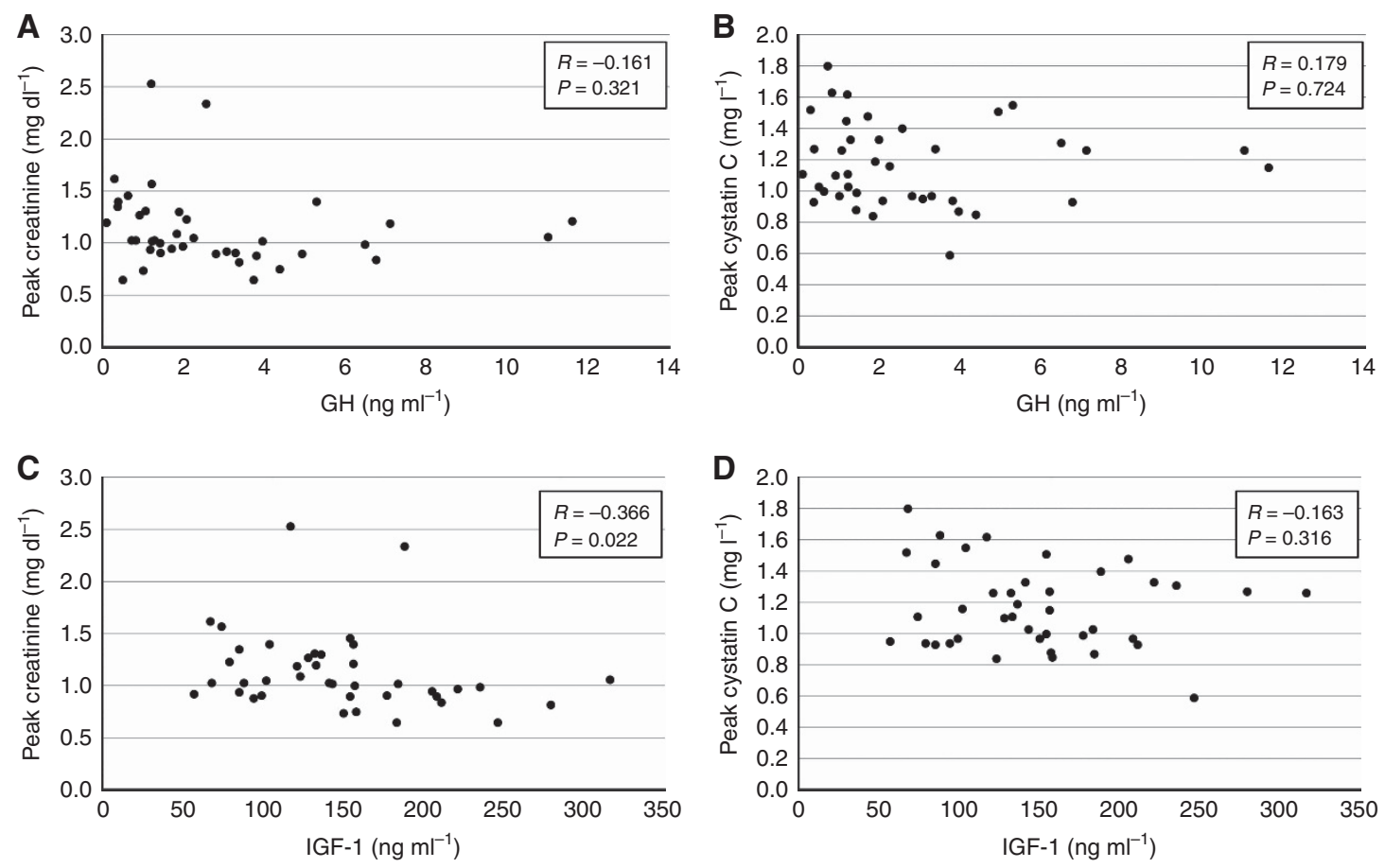

Figure 2. Relationships between renal dysfunction and growth factor concentrations. Relationship between (A) peak serum creatinine level during chemotherapy and growth hormone level on day 4; (B) peak serum cystatin C level during chemotherapy and growth hormone level on day 4; (C) peak serum creatinine level during chemotherapy and IGF-1 level on day 4 (D) peak serum cystatin $C$ level during chemotherapy and IGF-1 level on day 4. Serum creatinine levels were significantly correlated with serum IGF-1 levels. However, no statistical correlation was observed between serum creatinine and GH levels, serum cystatin C and GH levels, and serum cystatin C and IGF-1 levels.

Yao et al, 2007; Zhang et al, 2007; Gaspari et al, 2010). Vigorous intravenous hydration with saline combined with furosemide or mannitol reduces tubular toxicity by reducing cisplatin concentrations in renal tissue; however, these approaches are not always successful (Stark and Howel, 1978; Santoso et al, 2003). Although some renal protective agents such as magnesium and prostaglandin E1 have also been used in clinical practice, there is no conclusive evidence for the efficacy of these agents (Kidera et al, 2014; Yamamoto et al, 2015).

Ghrelin, a 28 -amino acid peptide predominantly produced by the stomach, stimulates the release of GH (Kojima et al, 1999; Nagaya et al, 2001) and IGF-1 (Akamizu and Kangawa, 2006; Veldhuis et al, 2008). Ghrelin also promotes appetite and gastrointestinal activity (Takata et al, 2015a). In humans, ghrelin receptor expression has been identified in the kidney, where it is predominantly located in the tubules rather than the glomerulus (Kemp et al, 2011). Some in vivo and in vitro studies support a powerful renal protective effect of ghrelin (Wang et al, 2009; Kemp et al, 2011). A previous report showed that ghrelin increases serum $\mathrm{GH}$ and IGF-1 concentrations and that IGF-1 has renal protective effects. IGF-1 binds to the IGF-1 receptor and phosphorylates insulin receptor substrate-2 (IRS-2). The IGF-1/IRS-2 pathway releases nitric oxide $(\mathrm{NO})$ via the activation of phosphatidyl inositol-3 kinase and its downstream effector Akt. Activated PI3k/ Akt increases the release of $\mathrm{NO}$, which has various effects, including anti-apoptotic, anti-ROS, and anti-inflammatory activity 
Table 4. Effect of ghrelin administration on the second cycle of DCF chemotherapy

\begin{tabular}{|c|c|c|c|}
\hline & $\begin{array}{l}\text { Ghrelin group } \\
\quad(n=16)\end{array}$ & $\begin{array}{l}\text { Control group } \\
\quad(n=16)\end{array}$ & $P$-value \\
\hline Docetaxel, \% ${ }^{a}$ & $93.9 \pm 9.6$ & $86.5 \pm 10.1$ & 0.016 \\
\hline Cisplatin, $\%^{a}$ & $92.7 \pm 10.1$ & $83.0 \pm 13.6$ & 0.012 \\
\hline 5-fluorouracil, \% ${ }^{\mathbf{a}}$ & $93.9 \pm 9.6$ & $85.5 \pm 9.3$ & 0.022 \\
\hline $\begin{array}{l}\text { Delay in the second } \\
\text { cycle of DCF, days }\end{array}$ & $0.3 \pm 1.0$ & $3.4 \pm 3.8$ & 0.040 \\
\hline
\end{tabular}

Abbreviation: DCF = docetaxel, cisplatin, and 5-fluorouracil combination chemotherapy.

${ }^{a}$ Ratio of the dose in the second cycle to the dose in the first cycle.

via the inhibition of TNF- $\alpha$, resulting in increased glomerular filtration and renal perfusion via vasodilation (Datta et al, 1997; Franke et al, 1997; Hemmings, 1997; Kulik et al, 1997; Chevalier et al, 2000; Luo et al, 2000; Wang et al, 2009; Cao et al, 2013). IGF1 also exerts its anti-fibrogenic effects through promotion of tubular remodelling. IGF-1 attenuates apoptosis-related interstitial fibrosis via other mechanisms (Gobe et al, 1999; Chevalier et al, 2000). These results suggest the molecular mechanisms underlying the renal protective effect of ghrelin against cisplatin-induced nephrotoxicity. In fact, our previous study showed that blood ghrelin concentrations are decreased to $\sim 60 \%$ of pre-chemotherapy levels early in the course of cisplatin-based chemotherapy, and that lower plasma acyl ghrelin levels are associated with renal dysfunction during cisplatin-based chemotherapy (Yamamoto et al, 2013; Yanagimoto et al, 2016). Thus, we conducted this prospective interventional trial of ghrelin to test the hypothesis that it decreases the renal dysfunction induced by cisplatin nephrotoxicity.

In the ghrelin group, serum GH and IGF-1 concentrations on day 4 of chemotherapy increased approximately three- and twofold, respectively, compared with pre-chemotherapy levels. The ghrelin group had significantly lower serum creatinine and cystatin $\mathrm{C}$ levels during chemotherapy than the control group. In addition, serum creatinine levels were significantly correlated with serum IGF-1 levels. These results suggest that IGF-1, which is regulated by ghrelin, may attenuate nephrotoxicity associated with cisplatin. Moreover, preventing renal dysfunction by ghrelin administration reduces the length of delay in initiation and amount of dose reduction in the second cycle of chemotherapy. Currently, hydration and diuretics during cisplatin-based chemotherapy are used to prevent renal dysfunction, but they are not always successful in preventing renal dysfunction. Ghrelin may be a novel strong supportive therapy for cisplatin-based chemotherapy that can improve patient QOL and prognosis by reducing nephrotoxicity and harmful effects associated with cisplatin during subsequent chemotherapy.

In the present study, dose reductions in docetaxel and 5 -fuluorouracil during the second cycle were also smaller in the ghrelin group than in the placebo group, although these reductions were based on adverse events other than renal dysfunction. This difference could be due to a lower incidence of febrile neutropenia, anorexia, nausea, and fatigue in the ghrelin group, although there were no statistically significant differences between the two groups. There were 5 patients who met the criteria for docetaxel, cisplatin, and 5-fluorouracil dose reduction in the second cycle in the ghrelin group and 10 in the placebo group (There were no patients who met the criteria for cisplatin dose reduction due to renal toxicity in the ghrelin group, compared with 2 patients in the placebo group). Hiura demonstrated that ghrelin administration during chemotherapy prevents anorexia, nausea, and decreasing health status using the European Organization for Research and Treatment of Cancer Core-30 Quality of Life Questionnaire (Hiura et al, 2012). Himpe et al (2008) reported that IGF-1 inhibits neutrophil apoptosis via the PI3k pathway, and that the effect of IGF-1 is comparable in magnitude to the effect of colony-stimulating factor. Their findings support our results, suggesting that ghrelin might reduce the frequency of adverse events other than renal dysfunction.

Direct IGF-1 administration might prevent renal dysfunction associated with cisplatin. Hammerman reported that direct IGF-1 administration exerts a renal protective effect on patients with low to moderate renal dysfunction or end-stage chronic renal failure by increasing renal plasma flow and glomerular filtration rate (Hammerman and Miller, 1994). However, there are no available data on the safety and efficacy of IGF-1 treatment for patients with malignancy, although some clinical data on ghrelin are available. Therefore, it is unclear whether IGF-1 administration can safely exert a renal protective effect on patients undergoing chemotherapy.

This study had some limitations. First, the number of patients was small, and the study was conducted at a single centre. Second, the optimal dose, initiation timing, and duration of ghrelin therapy are not clear. In this study, the dose and duration of ghrelin therapy were based on our previous study. Ghrelin administration was started concurrently with pre-chemotherapy hydration (Takata et al, 2015a,b). Thus, additional studies might be needed to evaluate more suitable regimens of ghrelin therapy. Finally, ghrelin is not yet commercially available, and its clinical utility would have to be validated by more supporting evidence. A larger cohort study at multiple centres is needed to identify the optimal way to administer ghrelin to prevent cisplatin-associated nephrotoxicity.

\section{CONCLUSIONS}

This study demonstrated that continuous administration of synthetic ghrelin during cisplatin-based chemotherapy attenuates renal dysfunction and harmful effects on subsequent cycles of chemotherapy. Ghrelin may be a novel strong supportive agent for cisplatin-based chemotherapy that can improve patient QOL and prognosis.

\section{CONFLICT OF INTEREST}

The authors declare no conflict of interest.

\section{REFERENCES}

Akamizu T, Kangawa K (2006) Translational research on the clinical applications of ghrelin. Endocr J 53(5): 585-591.

Ando N, Kato H, Igaki H, Shinoda M, Ozawa S, Shimizu H, Nakamura T, Yabusaki H, Aoyama N, Kurita A, Ikeda K, Kanda T, Tsujinaka T, Nakamura K, Fukuda H (2012) A randomized trial comparing postoperative adjuvant chemotherapy with cisplatin and 5-fluorouracil versus preoperative chemotherapy for localized advanced squamous cell carcinoma of the thoracic esophagus (JCOG9907). Ann Surg Oncol 19(1): 68-74.

Cao Y, Tang J, Yang T, Ma H, Yi D, Gu C, Yu S (2013) Cardioprotective effect of ghrelin in cardiopulmonary bypass involves a reduction in inflammatory response. PLoS One 8(1): e55021.

Chevalier RL, Goyal S, Kim A, Chang AY, Landau D, LeRoith D (2000) Renal tubulointerstitial injury from ureteral obstruction in the neonatal rat is attenuated by IGF-1. Kidney Int 57(3): 882-890.

Dahal A, Bellows BK, Sonpavde G, Tantravahi SK, Choueiri TK, Galsky MD, Agarwal N (2014) Incidence of severe nephrotoxicity with cisplatin based on renal function eligibility criteria: indirect comparison meta-analysis. Am J Clin Oncol; e-pub ahead of print 12 May 2014; doi:10.1097/ COC.0000000000000081. 
Datta SR, Dudek H, Tao X, Masters S, Fu H, Gotoh Y, Greenberg ME (1997) Akt phosphorylation of BAD couples survival signals to the cell-intrinsic death machinery. Cell 91(2): 231-241.

Engstrom PF, Lavin PT, Klaassen DJ (1983) Phase II evaluation of mitomycin and cisplatin in advanced esophageal carcinoma. Cancer Treat Rep 67(7-8): 713-715.

Franke TF, Kaplan DR, Cantley LC (1997) PI3K: downstream AKTion blocks apoptosis. Cell 88(4): 435-437.

Gaspari F, Cravedi P, Mandala M, Perico N, de Leon FR, Stucchi N, Ferrari S, Labianca R, Remuzzi G, Ruggenenti P (2010) Predicting cisplatin-induced acute kidney injury by urinary neutrophil gelatinase-associated lipocalin excretion: a pilot prospective case-control study. Nephron Clin Pract 115(2): c154-c160.

Gobe G, Willgoss D, Hogg N, Schoch E, Endre Z (1999) Cell survival or death in renal tubular epithelium after ischemia-reperfusion injury. Kidney Int 56(4): 1299-1304.

Gonzales-Vitale JC, Hayes DM, Cvitkovic E, Sternberg SS (1977) The renal pathology in clinical trials of cis-platinum (II) diamminedichloride. Cancer 39(4): 1362-1371.

Hammerman MR, Miller SB (1994) Therapeutic use of growth factors in renal failure. J Am Soc Nephrol 5(1): 1-11.

Hara H, Tahara M, Daiko H, Kato K, Igaki H, Kadowaki S, Tanaka Y, Hamamoto Y, Matsushita H, Nagase M, Hosoya Y (2013) Phase II feasibility study of preoperative chemotherapy with docetaxel, cisplatin, and fluorouracil for esophageal squamous cell carcinoma. Cancer Sci 104(11): 1455-1460.

Hayes DM, Cvitkovic E, Golbey RB, Scheiner E, Helson L, Krakoff IH (1977) High dose cis-platinum diammine dichloride: amelioration of renal toxicity by mannitol diuresis. Cancer 39(4): 1372-1381.

Health and Services (2009) Common Terminology Criteria for Adverse Events (CTCAE) Version 4.0. National Institutes of Health, National Cancer Institute. Available at https://searchworks.stanford.edu/view/9100287.

Hemmings BA (1997) Akt signaling: linking membrane events to life and death decisions. Science 275(5300): 628-630.

Himpe E, Degaillier C, Coppens A, Kooijman R (2008) Insulin-like growth factor-1 delays Fas-mediated apoptosis in human neutrophils through the phosphatidylinositol-3 kinase pathway. J Endocrinol 199(1): 69-80.

Hiura Y, Takiguchi S, Yamamoto K, Kurokawa Y, Yamasaki M, Nakajima K, Miyata H, Fujiwara Y, Mori M, Doki Y (2012) Fall in plasma ghrelin concentrations after cisplatin-based chemotherapy in esophageal cancer patients. Int J Clin Oncol 17(4): 316-323.

Huang Q, Dunn 2nd RT, Jayadev S, DiSorbo O, Pack FD, Farr SB, Stoll RE, Blanchard KT (2001) Assessment of cisplatin-induced nephrotoxicity by microarray technology. Toxicol Sci 63(2): 196-207.

Iizuka T, Kakegawa T, Ide H, Ando N, Watanabe H, Tanaka O, Takagi I, Isono K, Ishida K, Arimori M, Endo M, Fukushima M (1992) Phase II evaluation of cisplatin and 5-fluorouracil in advanced squamous cell carcinoma of the esophagus: a Japanese Esophagea Oncology Group Trial. Jpn J Clin Oncol 22(3): 172-176.

Ilson DH, Saltz L, Enzinger P, Huang Y, Kornblith A, Gollub M, O’Reilly E, Schwartz G, DeGroff J, Gonzalez G, Kelsen DP (1999) Phase II trial of weekly irinotecan plus cisplatin in advanced esophageal cancer. J Clin Oncol 17(10): 3270-3275.

Jacobs C, Kaubisch S, Halsey J, Lum BL, Gosland M, Coleman CN, Sikic BI (1991) The use of probenecid as a chemoprotector against cisplatin nephrotoxicity. Cancer 67(6): 1518-1524.

Kemp BA, Howell NL, Gray JT, Keller SR, Nass RM, Padia SH (2011) Intrarenal ghrelin infusion stimulates distal nephron-dependent sodium reabsorption in normal rats. Hypertension 57(3): 633-639.

Kidera Y, Kawakami H, Sakiyama T, Okamoto K, Tanaka K, Takeda M, Kaneda H, Nishina S, Tsurutani J, Fujiwara K, Nomura M, Yamazoe Y, Chiba Y, Nishida S, Tamura T, Nakagawa K (2014) Risk factors for cisplatin-induced nephrotoxicity and potential of magnesium supplementation for renal protection. PLoS One 9(7): e101902.

Kobayashi S, Ueno M, Ohkawa S, Irie K, Goda Y, Morimoto M (2014) Renal toxicity associated with weekly cisplatin and gemcitabine combination therapy for treatment of advanced biliary tract cancer. Oncology 87(1): 30-39.

Kojima M, Hosoda H, Date Y, Nakazato M, Matsuo H, Kangawa K (1999) Ghrelin is a growth-hormone-releasing acylated peptide from stomach. Nature 402(6762): 656-660.

Kulik G, Klippel A, Weber MJ (1997) Antiapoptotic signalling by the insulinlike growth factor I receptor, phosphatidylinositol 3-kinase, and Akt. Mol Cell Biol 17(3): 1595-1606.
Luo Z, Fujio Y, Kureishi Y, Rudic RD, Daumerie G, Fulton D, Sessa WC, Walsh K (2000) Acute modulation of endothelial Akt/PKB activity alters nitric oxide-dependent vasomotor activity in vivo. J Clin Invest 106(4): 493-499.

Minsky BD, Pajak TF, Ginsberg RJ, Pisansky TM, Martenson J, Komaki R, Okawara G, Rosenthal SA, Kelsen DP (2002) INT 0123 (Radiation Therapy Oncology Group 94-05) phase III trial of combined-modality therapy for esophageal cancer: high-dose versus standard-dose radiation therapy. J Clin Oncol 20(5): 1167-1174.

Nagaya N, Kojima M, Uematsu M, Yamagishi M, Hosoda H, Oya H, Hayashi Y, Kangawa K (2001) Hemodynamic and hormonal effects of human ghrelin in healthy volunteers. Am J Physiol Regul Integr Comp Physiol 280(5): R1483-R1487.

Ostrow S, Egorin MJ, Hahn D, Markus S, Aisner J, Chang P, LeRoy A, Bachur NR, Wiernik PH (1981) High-dose cisplatin therapy using mannitol versus furosemide diuresis: comparative pharmacokinetics and toxicity. Cancer Treat Rep 65(1-2): 73-78.

Pucci L, Triscornia S, Lucchesi D, Fotino C, Pellegrini G, Pardini E, Miccoli R, Del Prato S, Penno G (2007) Cystatin C and estimates of renal function: searching for a better measure of kidney function in diabetic patients. Clin Chem 53(3): 480-488.

Santoso JT, Lucci 3rd JA, Coleman RL, Schafer I, Hannigan EV (2003) Saline, mannitol, and furosemide hydration in acute cisplatin nephrotoxicity: a randomized trial. Cancer Chemother Pharmacol 52(1): 13-18.

Stark JJ, Howel SB (1978) Nephrotoxicity of cis-platinum (II) dichlorodiammine. Clin Pharmacol Ther 23(4): 461-466.

Takata A, Takiguchi S, Miyazaki Y, Miyata H, Takahashi T, Kurokawa Y, Yamasaki M, Nakajima K, Mori M, Kangawa K, Doki Y (2015a) Randomized Phase II Study of the anti-inflammatory effect of ghrelin during the postoperative period of esophagectomy. Ann Surg 262(2): 230-236.

Takata A, Takiguchi S, Murakami K, Miyazaki Y, Miyata H, Takahashi T, Kurokawa Y, Yamasaki M, Nakajima K, Mori M, Kangawa K, Doki Y (2015b) Effects of ghrelin administration on the early postoperative inflammatory response after esophagectomy. Surg Today 45(8): 1025-1031.

Takeda R, Nishimatsu H, Suzuki E, Satonaka H, Nagata D, Oba S, Sata M, Takahashi M, Yamamoto Y, Terauchi Y, Kadowaki T, Kangawa K, Kitamura T, Nagai R, Hirata Y (2006) Ghrelin improves renal function in mice with ischemic acute renal failure. J Am Soc Nephrol 17(1): 113-121.

Tanaka A, Suemaru K, Araki H (2007) A new approach for evaluating renal function and its practical application. J Pharmacol Sci 105(1): 1-5.

Therasse P, Arbuck SG, Eisenhauer EA, Wanders J, Kaplan RS, Rubinstein L, Verweij J, Van Glabbeke M, van Oosterom AT, Christian MC, Gwyther SG (2000) New guidelines to evaluate the response to treatment in solid tumors. European Organization for Research and Treatment of Cancer, National Cancer Institute of the United States, National Cancer Institute of Canada. J Natl Cancer Inst 92(3): 205-216.

Vasileiou I, Patsouras D, Patsouris E, Theocharis S (2013) Ghrelin and toxicity: recent findings and future challenges. J Appl Toxicol 33(4): 238-245.

Veldhuis JD, Reynolds GA, Iranmanesh A, Bowers CY (2008) Twenty-four hour continuous ghrelin infusion augments physiologically pulsatile, nycthemeral, and entropic (feedback-regulated) modes of growth hormone secretion. J Clin Endocrinol Metabol 93(9): 3597-3603.

Wang W, Bansal S, Falk S, Ljubanovic D, Schrier R (2009) Ghrelin protects mice against endotoxemia-induced acute kidney injury. Am J Physiol Renal Physiol 297(4): F1032-F1037.

Yamamoto K, Takiguchi S, Miyata H, Miyazaki Y, Hiura Y, Yamasaki M, Nakajima K, Fujiwara Y, Mori M, Kangawa K, Doki Y (2013) Reduced plasma ghrelin levels on day 1 after esophagectomy: a new predictor of prolonged systemic inflammatory response syndrome. Surg Today 43(1): $48-54$.

Yamamoto Y, Watanabe K, Tsukiyama I, Matsushita H, Yabushita H, Matsuura K, Wakatsuki A (2015) Nephroprotective effects of hydration with magnesium in patients with cervical cancer receiving cisplatin. Anticancer Res 35(4): 2199-2204.

Yamasaki M, Miyata H, Tanaka K, Shiraishi O, Motoori M, Peng YF, Yasuda T, Yano M, Shiozaki H, Mori M, Doki Y (2011) Multicenter phase I/II study of docetaxel, cisplatin and fluorouracil combination chemotherapy in patients with advanced or recurrent squamous cell carcinoma of the esophagus. Oncology 80(5-6): 307-313. 
Yanagimoto Y, Takiguchi S, Miyazaki Y, Makino T, Takahashi T, Kurokawa Y, Yamasaki M, Miyata H, Nakajima K, Mori M, Doki Y (2016) Plasma ghrelin levels as a predictor of adverse renal events due to cisplatin-based chemotherapy in patients with esophageal cancer. Jpn J Clin Oncol 46(5): 421-426.

Yao X, Panichpisal K, Kurtzman N, Nugent K (2007) Cisplatin nephrotoxicity: a review. Am J Med Sci 334(2): 115-124.

Zhang B, Ramesh G, Norbury CC, Reeves WB (2007) Cisplatin-induced nephrotoxicity is mediated by tumor necrosis factor-alpha produced by renal parenchymal cells. Kidney Int 72(1): 37-44.
Zwelling LA, Kohn KW (1979) Mechanism of action of cisdichlorodiammineplatinum(II). Cancer Treat Rep 63(9-10): 1439-1444.

This work is published under the standard license to publish agreement. After 12 months the work will become freely available and the license terms will switch to a Creative Commons AttributionNonCommercial-Share Alike 4.0 Unported License.

Supplementary Information accompanies this paper on British Journal of Cancer website (http://www.nature.com/bjc) 